\title{
Calculation of Electric Field at Ground Surface and ADSS Cable Prepared Hanging Point near EHV Power Transmission Tower
}

\author{
Bao-Qing $\mathrm{Xu}^{1}$, Xiao-Qiang Ma ${ }^{1}$, Sen $\mathrm{Lv}^{1}$, Biao Li ${ }^{1}$ and Lu Wang ${ }^{2}$ \\ ${ }^{1}$ Sanmenxia Power Supply Company, State Grid Henan Electric Power Company, Sanmenxia, China \\ ${ }^{2}$ North China Electric Power University, Baoding, China
}

\begin{abstract}
A simplified model of the $750 \mathrm{kV}$ tower is established by CDEGS software which is based on the Method Of Moment. The power frequency electric field distribution on the ground is achieved by software calculation and field-measuring. The validity of the calculation is proved when compare the calculation and experiment results. The model also can be used to calculate the electric field in prepared hanging points on the tower. Results show that the electric field distribution on the ground surface around the tower and prepared hanging points are meet the standard by calculation and experiment.
\end{abstract}

\section{Introduction}

With the rapid development of the national power grid construction, there are many applications of ADSS (All Dielectric Self-Supporting) cables for electric power communication system. Most of the ADSS cables are used for replace the aging communication line. But the research on ADSS is still not perfect at home and abroad. There are problems on the sheath resistant to electric corrosion, designing of line construction, electrical fittings equipped method. It is very important to master and apply technology of ADSS cables.

According to [1]-[3], in the power frequency electric field environment of the $750 \mathrm{kV}$ double circuit lines on the same tower even multi-circuit transmission line, the largest electric field near the house is $4 \mathrm{kV} / \mathrm{m}$; In the general area, such as the public activities area, area that the line across the road, the electric field is limited to 7 $\mathrm{kV} / \mathrm{m}$; the electric field is limited to $10 \mathrm{kV} / \mathrm{m}$ when the transmission line across farmland to avoid the uncomfortable feeling caused by the discharge; In remote areas sparsely populated, the area of non-public activities area or person passing through occasionally, the limit value of the electric field can be relaxed to $12 \mathrm{kV} / \mathrm{m}$.

Hanging points of ADSS cables is selected reasonably will ensure the cables in a small electric field environment. The position choice of ADSS cable hanging points is determined by the potential $(12 \mathrm{kV}, 25 \mathrm{kV})$ generally. But the researcher proposed that the main factor that affects the electric corrosion is the electric field strength at the cable hanging points. At present, electric field less than $10 \mathrm{kV} / \mathrm{m}$ at the hanging points set as standard generally [2-4].

The effectiveness of CDEGS software based on Method of Moments has been verified in literature [4].
Charge Simulation Method was used in [5] to calculate the electric field generated by transmission lines, and the method is effective, but charge simulation method to calculate the electric field is more complicated in several cases such as consider the earth to non-perfect conductor, and taking into account the ground portion of the tower. Charge simulation method is generally used to analyze the current model. The frequency electric field of $500 \mathrm{kV}$ transmission line was calculated based on charge simulation method, and the influence of the electric field to the environment of tower was analyzed in literature [6]. Three-dimensional frequency electric field near high voltage transmission towers was calculated based on three-dimensional electric field computational method. Detailed distribution of three-dimensional frequency electric field was obtained in literature [7], and low field position fitting to ADSS cable suspension was achieved. The damage mechanism and countermeasures of ADSS optical cable in electric stress was analyzed detailedly in literature [3]

In this paper, CDEGS software is used to build the $750 \mathrm{kV}$ linear iron tower model. The distribution of the surface field strength of the tower is calculated, the correctness of the simulation was verified by experiment. And then the model is used to calculate the electric field strength of the prepared hanging points of cable in the tower to determine the reliability of the position.

\section{Calculation principle}

The method of moment is to transform the integral equation problem into a matrix equation. The numerical solution of the matrix equation is achieved by computer calculate[5]. Based on the numerical solution of the driving source distribution, the radiation field distribution 
and the wave impedance and other parameters can be calculated. The potential difference between two points on the conductor surface is determined by the leakage current. The electric potential difference between two points in the conductor section is generated by the self impedance and the axial current flowing through the conductor. The axial current on the conductor section can be expressed by the leakage current of each conductor section. The leakage current can be achieved by equations established by leakage currents as unknown quantity. The electric field near the transmission line can be obtained by leakage current[8-9].

\section{Computational model}

The $750 \mathrm{kV}$ double-circuit lines straight tower has been set as an example using CDEGS. The line voltage is $750 \mathrm{kV}$ and the phase conductor type is LGJ-400/50, 6bundle transmission line is applied, and the spacing between intra-bundle conductors is $0.55 \mathrm{~m}$, right and left phase sequence are respectively as $\mathrm{C} / \mathrm{B} / \mathrm{A}$ and $\mathrm{A} / \mathrm{B} / \mathrm{C}$. the ground wires type is JLB20A-150 and the diameter is $3.15 \mathrm{~mm}$, the span that in front of the tower and behind the tower are respectively $488 \mathrm{~m}$ and $448 \mathrm{~m}$. Arc sag of transmission line left the tower is 13 meters, and arc sag of transmission line right the tower is 11 meters in figure 3. The earth is regarded as single uniform soil in the model, and the soil resistivity is $100 \Omega \cdot \mathrm{m}$. The two prepared hanging points of telecommunication optical fiber cables are respectively located at 12 meters and 11.46 meters high of the tower, as shown in figure 4 .

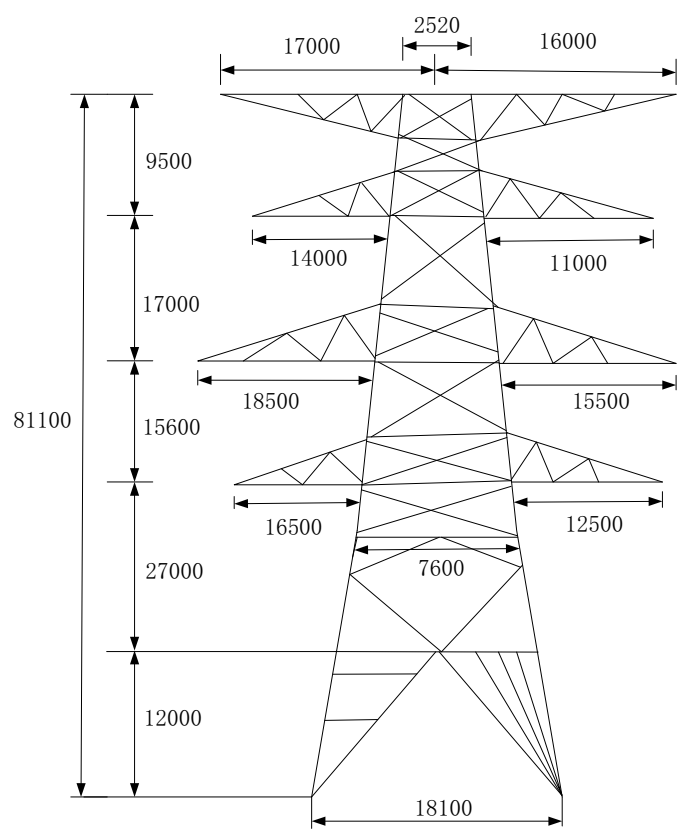

Figure 1. Tower geometry structure

The tower is needed to be simplified in the modeling process because of its complex structure, some factors such as the secondary metal components and insulator strings are ignored, the main metal frame is retained, and the platform of the main tower is equivalent to the square.Tower geometry structure is shown in figure 1, and simplified tower model is shown in figure 2. The wire arc sag is shown in figure 3 .

Line voltage is change according to the law of symmetrical three-phase sine, and effective value is applied in calculation. The rated line voltage is $750 \mathrm{kV}$, and calculated Voltage is 1.05 times greater than rated voltage when considering the actual operation. That is,

$$
\begin{gathered}
\dot{U}_{A}=\frac{750 \times 1.05}{\sqrt{3}} \mathrm{kV} \\
\dot{U}_{B}=\frac{750 \times 1.05}{\sqrt{3}} \angle-120^{\circ} \mathrm{kV} \\
\dot{U}_{C}=\frac{750 \times 1.05}{\sqrt{3}} \angle 120^{\circ} \mathrm{kV}
\end{gathered}
$$

Electric field of two prepared hanging points and the distribution of electric field on OA, OD and DF are calculated, these position shown in figure 4 .



Figure 2. Simplified tower model

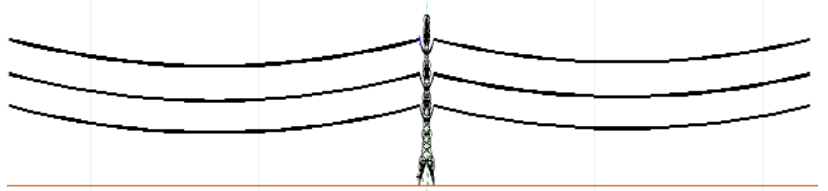

Figure 3. Left view of simplified tower model



Figure 4. Position schematic diagram 
The calculation results of ground surface field near the tower are shown in figure 5.

The calculation results of electric field of two prepared hanging points are shown in table 1.

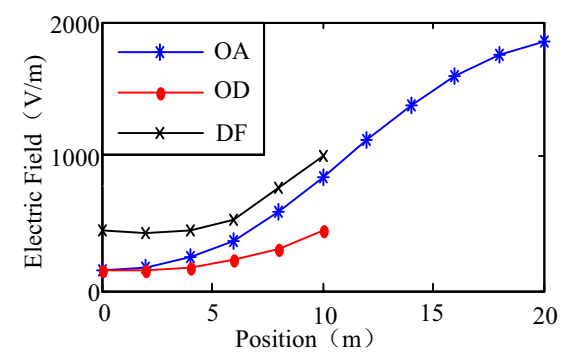

Figure 5. Calculation results of surface field

Table 1. Calculation of prepared hanging points

\begin{tabular}{|c|c|}
\hline Prepared Hanging Point & $\begin{array}{c}\text { Electric Field Intensity } \\
(\mathbf{k V} / \mathbf{m})\end{array}$ \\
\hline hang point 1 & 7.37 \\
\hline hang point 2 & 6.43 \\
\hline
\end{tabular}

\section{Experimental measurement}

Only the surface field strength can be measured in this experiment because of the tower charged operation. 750 $\mathrm{kV}$ tower center is selected to carry out measuring the electric field intensity under the transmission lines, as shown in figure 4 .

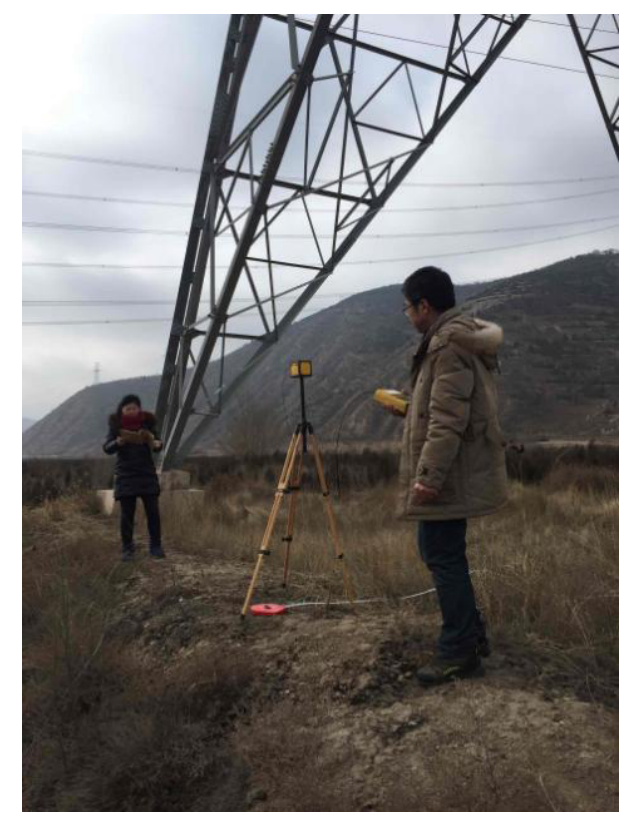

Figure 6. Scene measure graph

EFA-300 electromagnetic field analyzer was applied in measurement, with temperature of $70 \mathrm{C}$ and humidity of $45 \%$. The method of measurement refers to GBT 12720-1991 Power frequency electric field measurement and DLT 988-2005 Methods of measurement of power frequency electric field and magnetic field from high voltage overhead power transmission line and substation.

(1)The measurement of surface electric field: Schematic diagram of tower and transmission line is shown in figure 4. Measured height is 1.5 meter. The electric field intensity of the three lines around the iron tower that one measuring points per two meters are measured, which is $\mathrm{OA}$ (the tower center to 10 meters outside the tower)、OD(tower center to tower foot)、 $\mathrm{DF}$ (center of tower lateral to tower foot) respectively. Test data and calculation data are both effective value.

(2) The measurement of electric field of two prepared hanging points: The electric field intensity of two pre hang points of communication optical cable were measured, as shown in figure 4 , the electric field measuring probe was fixed to the insulating rod, the insulating rod was fixed to the edge of the tower by the operator. The specific position of the probe is determined by the laser range finder, and the distance of probe and tower is $10 \mathrm{~cm}$. Test data and calculation data are effective value.

The measurement results are shown in figure 7.

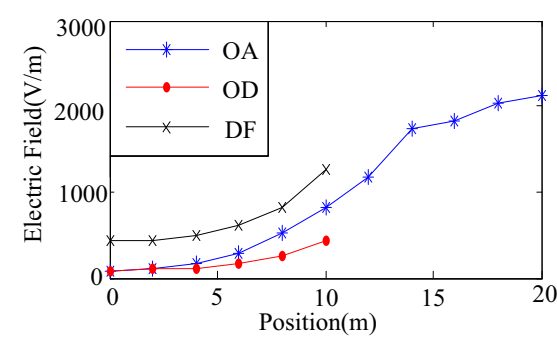

Figure 7. Measurement results of surface field

Table 2. Measurement results of prepared hanging points

\begin{tabular}{|c|c|}
\hline Prepared Hanging Point & $\begin{array}{c}\text { Electric Field Intensity } \\
(\mathbf{k V} / \mathbf{m})\end{array}$ \\
\hline hang point 1 & 7.17 \\
\hline hang point 2 & 6.00 \\
\hline
\end{tabular}

\section{Analysis}

\subsection{Surface field strength comparison results}

The comparison of OA direction between the measured results and the simulation results is shown in table 3 .

The comparison of OD direction between the measured results and the simulation results is shown in table 4.

The comparison of DF direction between the measured results and the simulation results is shown in table 5.

The comparison of prepared hanging point between the measured results and the simulation results is shown in table 6 . 
Table 3. OA direction comparison results $(\mathrm{V} / \mathrm{m})$

\begin{tabular}{|c|c|c|c|}
\hline $\begin{array}{c}\text { Observation } \\
\text { position }\end{array}$ & Measurement & Simulation & Error\% \\
\hline 0 & 81.3 & 99.5 & 22.2 \\
\hline 2 & 140.2 & 118 & 13.2 \\
\hline 4 & 166.2 & 185 & 11.3 \\
\hline 6 & 279.1 & 185 & 13.5 \\
\hline 8 & 518 & 525 & 1.3 \\
\hline 10 & 815.8 & 795 & 2.5 \\
\hline 12 & 1173 & 1080 & 7.9 \\
\hline 14 & 1740 & 1350 & 22.4 \\
\hline 16 & 1821 & 1570 & 13.7 \\
\hline 18 & 2026 & 1730 & 14.6 \\
\hline 20 & 2131 & 1840 & 13.6 \\
\hline
\end{tabular}

Table 4. OD direction comparison results (V/m)

\begin{tabular}{|c|c|c|c|c|c|c|}
\hline $\begin{array}{c}\text { Observation } \\
\text { position }\end{array}$ & $\mathbf{0}$ & $\mathbf{2}$ & $\mathbf{4}$ & $\mathbf{6}$ & $\mathbf{8}$ & $\mathbf{1 0}$ \\
\hline measurement & 81.38 & 89.83 & 108.3 & 153.3 & 263.1 & 434.7 \\
\hline simulation & 99.5 & 105 & 127 & 181 & 278 & 412 \\
\hline error\% & 22.2 & 16.8 & 17.2 & 18.0 & 5.6 & 5.1 \\
\hline
\end{tabular}

Table 5. DF direction results comparison $(\mathrm{V} / \mathrm{m})$

\begin{tabular}{|c|c|c|c|c|c|c|}
\hline $\begin{array}{c}\text { Observation } \\
\text { position }\end{array}$ & $\mathbf{0}$ & $\mathbf{2}$ & $\mathbf{4}$ & $\mathbf{6}$ & $\mathbf{8}$ & $\mathbf{1 0}$ \\
\hline measurement & 434.7 & 433.7 & 484.1 & 602.8 & 828.5 & 1250 \\
\hline simulation & 445 & 435 & 453 & 517 & 756 & 1000 \\
\hline error\% & 2.4 & 0.3 & 6.4 & 14.2 & 8.7 & 20 \\
\hline
\end{tabular}

Table 6. Comparison results of prepared hanging Points

\begin{tabular}{|c|c|c|}
\hline $\begin{array}{c}\text { Prepared } \\
\text { Hanging Point }\end{array}$ & Hang Point 1 (kV/m) & Hang Point 2 (kV/m) \\
\hline measurement & 7.17 & 6.00 \\
\hline simulation & 7.37 & 6.43 \\
\hline error\% & 2.7 & 7.2 \\
\hline
\end{tabular}

According to the above tables,

(1)Surface field strength measured values and simulated values are both limited to $4 \mathrm{kV} / \mathrm{m}$ within the safety limits.

(2)There is certain dispersion between the calculated values and the test values, but the trend is identical basically, and maximum error less-than 30\%. Therefore, the proposed method is feasible, and the model and calculation process are correct. The model can be used to analyze the potential distribution of electric field near the tower, and calculate prepared hanging points of communication optical cable, thus the ability to analyze the problem of electrical corrosion of ADSS is enhanced.

(3)After analyzing, the main reason for the error is the simplification of the tower model. In particularly, the horizontal steel structure of the 12 meter platform and multi-stage platforms above are not given. These multilayer horizontal steel structures is ignored in modeling process that have shielding effect on the electric field of transmission lines.

(4)The measuring point extends to 10 meters outside the tower along the OA direction, as seen from the table 2, after 10 meters the error is greater. This because there are a lot of trees outside the tower, and measurement probe cannot escape the trees that are difficult to ensure that the probe is in the vicinity of the 2.5 meter range to meet the measurement requirements. The ground surface of tower in a bad environment, the ground is uneven, and the gap is about $0.5-1 \mathrm{~m}$ that is difficult to match the position coordinates of the actual measurement points with the calculation points.

\subsection{Prepared hanging points calculation}

By the above analysis of surface field strength, the method and modeling process are proved to be effective, and prepared hanging points are calculated. The position of two prepared hanging points are located in 12 meters high of the tower, and the distance between the position and the wire lowest point is 20 meters, therefore, the electric field of prepared hanging points can be measured manually. The results of simulation and experiment are shown in table 6 , and the error less-than $10 \%$. Prepared hanging point 1 and prepared hanging point 2 both meet the standard of ADSS communication optical cable that electric field strength less than $10 \mathrm{kV} / \mathrm{m}$. Therefore, the selection of the position of the prepared hanging point is reliable.

\section{Conclusion}

The validity and effectiveness of the model built by CDEGS are proved by the comparison between measured and simulated results. The model can be used to calculate and analysis the distribution of electric field intensity that tower of different phase sequence, phase angle, the position near transmission line which cannot be measured directly and ADSS cable hanging point. Meanwhile, the surface field strength of the $750 \mathrm{kV}$ tower is verified to meet the requirements of the national standard that less than $4 \mathrm{kV} / \mathrm{m}$; and the calculation of electric field intensity of the prepared hanging point of the ADSS communication cable of the tower that meet the requirements of the national standard that less than $10 \mathrm{kV} / \mathrm{m}$. The analysis results can provide a theoretical basis for the analysis of the distribution of the electric field strength around the tower, the safety protection of live working on the super high voltage tower and the safety of the ADSS cable. 


\section{References}

1. G.-Z. Zhang, Y. Lu, B.-Q. Wan, X. Wu, Advances of power system and hydroelectric engineering 6, 30 (2007)

2. Y.-F. Zhou, Z.-T. Cao, Telecommunications for electric power system 11, 16 (2001)

3. D.-Q. Ding, Telecommunications for electric power system 9, 1 (2001)

4. B. Zhang, X. Cui, T.-B. Lu, L. Li, Z.-B. Zhao, Power System Technology 27, 5 (2003)

5. T.-B. Lu, K. Xiao, B. Zhang, High voltage technology 3, 24 (2001)

6. Y.-M. Li, Y.-Z. Fan, L.-W. Xu, Power system technology 3, 782 (2013)

7. X. Cui, F.-C. Wang, T.-B. Lu, C. Zhong, Telecommunications for electric power system 2, 12 (2004)

8. Z.-B. Zhao, X. Cui, B. Zhang, L. Li, Proceedings of the CSEE 24, 148 (2004)

9. G.-Z. Ni, S.-Y. Yang, J. Qiu, Numerical calculation of engineering magnetic field (China Machine Press, 2012) 